\title{
Does the Transcontinental Escalation of Zika Virus Infection Pose a Major Global Threat to Human Health and are Current Public and Media Concern Justified?
}

\author{
Andrew W Taylor-Robinson
}

School of Medical and Applied Sciences, Central Queensland University, Brisbane, QLD 4000, Australia

Corresponding author: Professor Andrew W Taylor-Robinson, Infectious Diseases Research Group, School of Medical and Applied Sciences, Central Queensland University, Brisbane, QLD 4000, Australia, Tel: +61 73295 1185; Email: a.taylor-robinson@cqu.edu.au

Received date: October 21, 2016; Accepted date: November 24, 2016; Published date: December 01, 2016

Citation: Taylor-Robinson AW. Does the Transcontinental Escalation of Zika Virus Infection Pose a Major Global Threat to Human Health and are Current Public and Media Concern Justified? J Prev Inf Cntrl. 2016, 2:2.

Copyright: (C) 2016 Taylor-Robinson AW. This is an open-access article distributed under the terms of the Creative Commons Attribution License, which permits unrestricted use, distribution, and reproduction in any medium, provided the original author and source are credited.

\section{Abstract}

The Zika virus is transmitted between humans primarily by the infectious bite of the Aedes aegypti and A. albopictus species of daytime-feeding mosquito. The infection so caused emerged explosively in South America 18 months ago, with the primary impact of thousands of babies born with microcephaly, a serious neurological defect. Although the epidemic that was centred initially in Brazil has since spread throughout Latin America, the rate of its progress to other regions of the globe has not been as rapid as was first predicted. This has enabled the public health surveillance systems in countries in North America, Europe and the Asia Pacific region to be placed on high alert for the detection of clinical cases in, for instance, travellers returning from known Zika-endemic zones. This has contributed to reducing the likely future impact of Zika on regions that are not currently affected. This should act to dampen the media frenzy that accompanied preparation for the recent Rio de Janeiro Olympic and Paralympic Games concerning not only the local impact but the threat of a global pandemic. However, a significant caveat is that the geographical distribution of vector mosquitoes may be modified by climate change, with an incrementally increasing range; this should be monitored assiduously in order to prepare for the risk of local outbreaks in areas previously free of infection. It should be stressed that in developing countries situated in tropical and subtropical climates, where public health provision is not as well-established as in industrialised nations, there may remain a significant threat of Zika epidemics for years to come. On a positive note, a unified vector control and prevention strategy can encompass Zika and the closely related yellow fever, dengue and chikungunya arboviruses, which are all carried by the same Aedes mosquitoes. Thus, such a 'one size fits all' approach may help to combat the cause of several major tropical infectious diseases.

\section{Keywords:}

Zika; Arbovirus; Mosquito; Aedes; Transmission; Vector; Control; Prevention; Epidemic; Inequality

\section{Introduction}

Until very recently, the now infamous arbovirus Zika was known only as an esoteric curiosity of virology and tropical medicine research, recognised for over 60 years to infect humans at very low incidence in some parts of Africa, Asia and the Pacific islands [1]. This is the virus that has arisen in the last 18 months to cause an epidemic in South and Central America [2]. In many ways, Zika is a prime example of a re-emerging infectious disease; an old disease presenting in large numbers and in a new context. To date, at least 65 countries and territories are reported to have active Zika transmission (Figure 1) [3]. Most infections occur with either very mild flu-like symptoms or, far more often, are in fact subclinical. However, it is a starkly contrasting concern for new-born babies, who can suffer from a congenital condition called microcephaly, literally possessing an abnormally small head - hence an underdeveloped brain [4]. In Brazil, the centre of the current outbreak, more than 5,000 cases of babies born with brain defects have been recorded [5]. These appear to be associated with Zika infection of the pregnant mother, from whom it is passed to the foetus in her womb (Figure 2) [6].

\section{Local impact of Zika on the Olympic Games - and beyond}

During the first half of 2016 headlines in the news media surrounding this new and sudden epidemic of Zika infection were powerfully evocative on a visceral psychological level, which was intensified by an exaggerated fear instilled by the unsettling images of infants with undersized heads [7]. The world became very concerned about the risks of a Zika pandemic [8], a level of hysteria that was compounded by the massive level of publicity in broadcasting, print and social media surrounding how the threat of infection, real or perceived, might impact on the now completed sporting showpieces of the Rio de Janeiro Olympic and Paralympic Games [9]. 


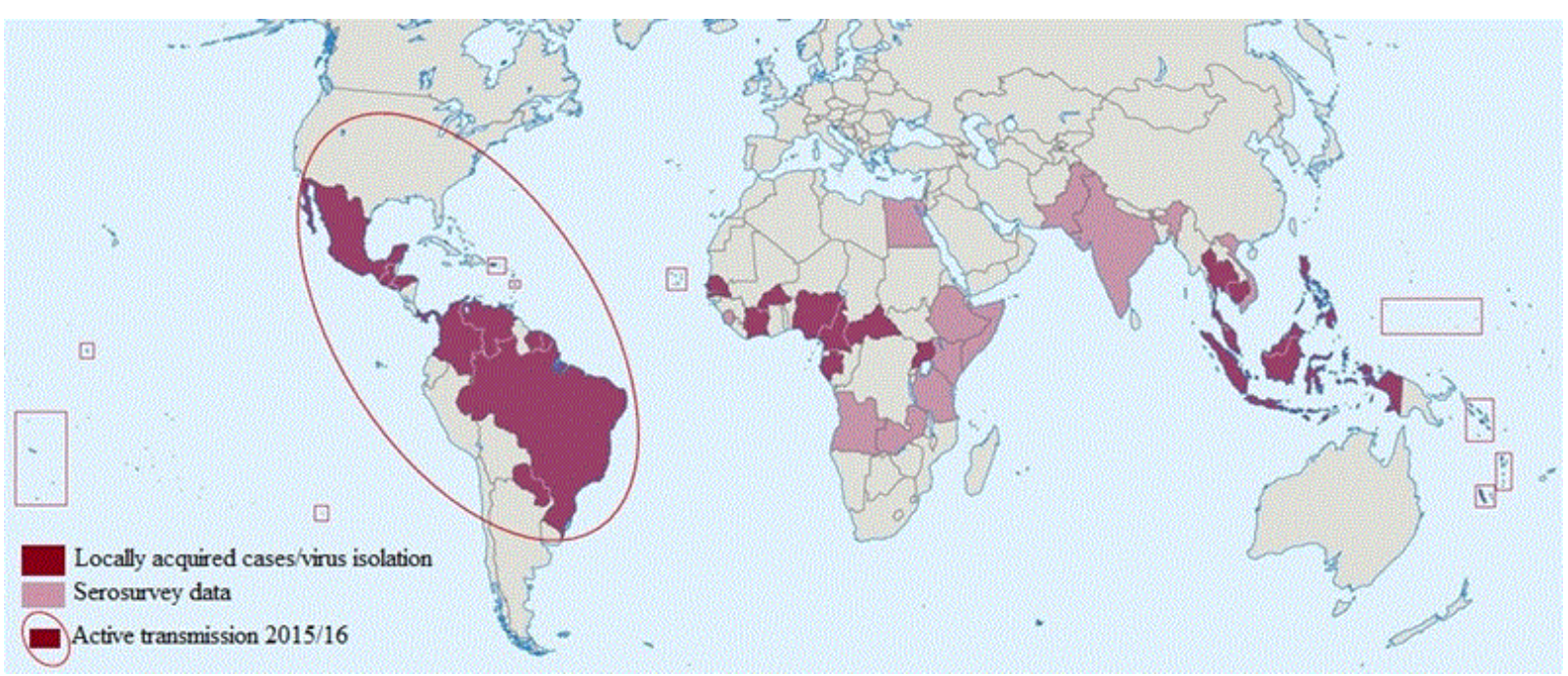

Figure 1 Map showing current distribution of known Zika virus transmission. Modified from reference [5].

The risk to competitors, volunteers and spectators of contracting infection, and the consequences this may have on their health and that of their families, was debated at great length $[10,11]$. Some high-profile athletes pulled out due to fear of becoming ill or of infecting any child that they may plan to have in future. As events transpired, there was not even a single laboratory-confirmed case of Zika notified for anyone associated with either competition over its duration [12].

In hindsight was this attention vindicated or can it be considered a disproportionate reaction? Well, the answer to both questions is yes. Zika is a flavivirus that is typically passed between people by the infectious bite of either of two particular species of mosquito, Aedes aegypti and A. albopictus [13]. An especially heavy rainy season in Brazil at the start of 2016 triggered a sudden eruption in numbers of these mosquitoes, which were responsible for the subsequent wave of Zika cases in humans. Once the regional authorities recognised the problem, with the assistance of military personnel affected areas were sprayed exhaustively with insecticide [14]. With vanishingly few mosquitoes to act as vectors of virus transmission, the risk of a person becoming infected is reduced dramatically. This is to not disregard the isolated preliminary reports of contracting Zika via unprotected sexual intercourse with an infected person, for which the aetiology of disease remains unconfirmed [15].

The impact of Zika on the preparations for the Olympics was therefore very real but in fact it may not have affected the staging of the sporting competition itself irrespective of any vector control measures that were put into operation. August is the driest and equal coldest month of the year in Brazil, a time when it is highly unlikely to trap a mosquito in the vicinity of Rio, not to mention actually be bitten by one [14]. Of course, the predicted increase in precipitation towards the end of this year may well lead to another spike of clinical cases of Zika, but possibly not as pronounced as the first due to the development of herd immunity among the local populous in response to prior exposure to the virus [16]. This is a valid cause for renewed concern for the public health programs of nations across Latin
America, this time after the attention of the world's media has largely turned elsewhere.

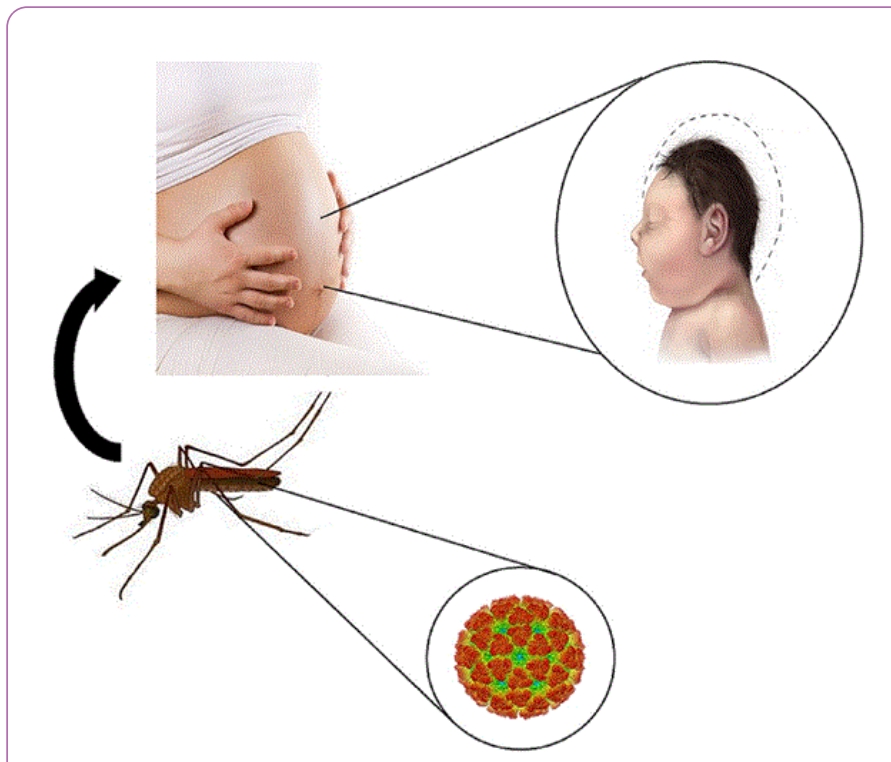

Figure 2 Zika virus can be transmitted from a pregnant woman to her unborn child.

It is said that a little knowledge is a dangerous thing; so is a lot. Fuelled by media speculation $[7,8]$, ignorance and phobias concerning Zika have the potential to influence negatively the lives of people in currently affected locations long after the current epidemic has subsided [17]. This relates in particular to the development of anxiety among pregnant women and their families [18]. As a societal response to Zika, we have a collective responsibility to not spread misinformation or to promote gender inequality, inadvertently or otherwise. For that matter, this equally applies to the next re-emerging infectious disease that makes an impact on the international stage. 


\section{Strategies to combat Zika - present and future}

At present, there is no specific effective therapy to combat Zika. Intensive investigation is ongoing aimed at determining the role played by the virus in disease pathology and, in addition to microcephaly, if it is directly responsible for other possible neurological sequelae of infection [19]. This is complemented by research to develop an efficacious vaccine against Zika, a relatively simple enveloped, single-stranded, positive-sense RNA virus, towards which goal initial progress appears promising [20]. However, to produce a commercially available vaccine ultimately may require performing clinical trials in pregnant women, the group in which viral infection appears to have the most profound effect, for which study gaining ethical approval may not prove straightforward [21].

In the meantime, primary measures to prevent the virus from spreading even further involves a combination of lowtechnology methods based on vector control and disease surveillance reinforced by common sense advice [22]. These include insecticide treatment of residential communities, personal protection from mosquito bites, preventing pregnant women from travelling to Zika-endemic territories, and practicing safe sex in those countries.

\section{Global spread of Zika and risk to current non- endemic regions}

This begs the question: are people in places far distant to Brazil and which are currently Zika-free zones right to be concerned by its potential global spread? The answer depends on where you live - with respect to both the region and the country [23]. Cases of introduced infection, brought into a country by an infected traveller returning from a Zika-endemic territory, could happen almost anywhere, thanks to the pervasive nature of international air travel. Shipping freight is also a potential source of contaminated mosquito eggs and larvae. For a local outbreak to be sustained, however, requires Aedes mosquitoes to be endemic to the new site [24]. Since these do not fly at all far, maybe only 500 metres in a lifetime [25], high population densities of mosquitoes and humans would be required to overlap in order to facilitate the spread of infection [24]. Moreover, since Aedes inhabits tropical and subtropical regions [2], any virus that it transmits poses far less a threat of infection to those who reside in a more temperate climate.

Zika may yet spread globally but at a slower rate, and with less impact, than has been witnessed during the epidemic in South America. In spite of appreciable anxiety among the general public in response to media speculation, in regions where Zika has not gained a foothold, such as North America, Europe and Australia (Figure 1), right now it is highly likely that any outbreak would be contained locally [24]. This is especially true of industrialised nations for which there is an established public health infrastructure and excellent resources provided for disease surveillance and mosquito control programs [26]. Thus, given the significant capacity for mosquito control in developed countries, it is difficult to justify the widespread public and media concern.
In contrast, in developing countries in which there is insufficient funding or framework to support effective implementation of mosquito control programs it is probable that a Zika outbreak may not be restricted so readily [23]. Certainly, this appears to be the case for those nations across Latin America in which there is now active Zika transmission. The situation may arise where the inequality of public health care provision in neighbouring countries of varying affluence might be highlighted, South East Asia providing a ready example [27]. Hence, it is valid to consider Zika as an 'infectious disease of poverty' [23].

\section{Climate change may alter Zika distribution}

Finally, a warning for the future. Due to the effect of global warming, the geographical range of Aedes mosquitoes may be predicted to expand in the coming decades [2]. As a consequence of climate change, the worldwide distribution of Zika may also alter beyond the pattern that becomes established over the next couple of years. Thus, countries which are not affected at present or in the near future should not be complacent that they will always remain free of Zika. Future control strategies for Zika should be considered in tandem with the continuing threat to human well-being that is presented by yellow fever, dengue and chikungunya arboviruses, all of which are transmitted by the same vector species [11]. This further highlights the importance of vector control to the prevention of mosquito-borne infectious diseases.

\section{Conclusion}

In the current age of high-speed internet communication, 24 $\mathrm{h}$ rolling news and unregulated social media forums, the Zika virus infection that swept across Latin America in recent months has attracted unprecedented attention. Such a disproportionate level of interest was exacerbated by Rio de Janeiro playing host to the Olympic and Paralympic Games in August and September, respectively. These mass participation events concluded without a Zika-related incident and the world's media have now departed. However, the incidence of infection in Brazil is set to rise again soon, coincident with increasing rainfall which will foster an expansion of the local population of diseasetransmitting Aedes mosquitoes. Further afield, the impact of Zika is predicted to be less but just how effectively outbreaks are contained in individual countries will depend on the public health infrastructure and integrated vector control management that are in place to combat mosquito-borne infectious diseases. This may throw into sharp relief the inequality of investment in disease control measures and health service provision between nations of disparate economic strength.

\section{Conflict of Interest}

The author declares no competing issues of interest. 


\section{Acknowledgement}

The author's research is supported by Central Queensland University and the Australian Government's Collaborative Research Networks Program. 


\section{References}

1. Wikan N, Smith DR (2016) Zika virus: history of a newly emerging arbovirus. Lancet Infect Dis 16: e119-e126.

2. Pan American Health Organization (2016) Zika virus infection. http://www.paho.org/hq/index.php?option=com_content\&view= \%20article\&id=11585\&ltemid=41688\&lang=en.

3. Centers for Disease Control and Prevention (2016) All countries \& territories with active Zika virus transmission. http:// www.cdc.gov/zika/geo/active-countries.html.

4. Centers for Disease Control and Prevention (2016) Zika virus symptoms, testing \& treatment. http://www.cdc.gov/zika/ symptoms/.

5. Fauci AS, Morens DM (2016) Zika virus in the Americas - yet another arbovirus threat. N Engl J Med 374: 601-604.

6. Meaney-Delman D, Rasmussen SA, Staples JE, et al. (2016) Zika virus and pregnancy: what obstetric health care providers need to know. Obstet Gynecol 127: 642-648.

7. BBC News (2016) Zika virus: rumours and theories fuel 'information war'. http://www.bbc.com/news/world-latinamerica-35601808.

8. Samarasekera U, Triunfol M (2016) Concern over Zika virus grips the world. Lancet 387: 521-524.

9. Attaran A (2016) Zika virus and the 2016 Olympic Games. Lancet Infect Dis 16: 1001-1003.

10. Zumla A, McCloskey B, Bin Saeed AA, et al. (2016) What is the experience from previous mass gathering events? Lessons for Zika virus and the Olympics 2016. Int J Infect Dis 47: 1-4.

11. Massad E, Coutinho FA, Wilder-Smith A (2016) Is Zika a substantial risk for visitors to the Rio de Janeiro Olympic Games? Lancet 388 : 25.

12. Vargas L (2016) WHO says zero Zika cases tied to Olympics, Paralympics. http://www.talkmedianews.com/health/ 2016/09/23/who-says-zero-zika-cases-tied-olympicsparalympics/.

13. Diallo D, Sall AA, Diagne CT, et al. (2014) Zika virus emergence in mosquitoes in southeastern Senegal, 2011. PLoS One 9: e109442.

14. Byrne K (2016) Brazil Zika crisis: over 200,000 deployed in massive mitigation operation ahead of Rio Olympics. http:// www.accuweather.com/en/weather-news/brazil-zika-crisisover-200000-deployed-in-massive-mitigation-operation-aheadof-2016-rio-olympics/56709513.
15. Musso D, Roche C, Robin E, et al. (2015) Potential sexual transmission of Zika virus. Emerg Infect Dis. 21: 359-361.

16. Ferguson NM, Cucunubá ZM, Dorigatti I, et al. (2016) Countering the Zika epidemic in Latin America. Science 353: 353-354.

17. Taylor-Robinson A (2016) Zika-associated mental health burdens: is little knowledge a dangerous thing? BioMed Central On Health blog, 20 April. http://blogs.biomedcentral.com/on-health/ 2016/04/20/zika-associated-mental-health-burdens-littleknowledge-dangerous-thing/.

18. Davies S, Bennett B (2016) Zika and Ebola had a much worse effect on women: we need more research to address this in future. The Conversation, 20 October. http://theconversation.com/zika-andebola-had-a-much-worse-effect-on-women-we-need-moreresearch-to-address-this-in-future-64868.

19. Hayden EC (2016) Proving Zika link to birth defects poses huge challenge. Nature 530: 142-143.

20. Taylor-Robinson AW (2016) A vaccine effective against Zika virus is theoretically possible but may not be delivered anytime soon. Res Rep Trop Med 7: 11-15.

21. lacobucci G (2016) Zika highlights need for ethical framework for developing vaccines for pregnant women. Brit Med J 352: 11155.

22. World Health Organization (2012) Handbook for Integrated Vector Management. http://apps.who.int/iris/bitstream/10665/44768/1/ 9789241502801_eng.pdf.

23. Gyawali N, Bradbury RS, Taylor-Robinson AW (2016) The global spread of Zika virus: is public and media concern justified in regions currently unaffected? Infect Dis Poverty 5: 37.

24. Taylor-Robinson AW (2016) Local transmission of Zika infection is feasible in non-endemic developed countries but has limited potential to reach epidemic proportions. Insights Biomed 1: e3.

25. Muir LE, Kay BH (1998) Aedes aegypti survival and dispersal estimated by mark-release-recapture in northern Australia. Am J Trop Med Hyg 58: 277-282.

26. Taylor-Robinson AW (2016) Local transmission of Zika virus infection is possible in Australia but should be contained by current vector control measures. Infect Dis Vaccines: Open Access 1: 001.

27. Bogoch II, Brady OJ, Kraemer MU, et al. (2016) Potential for Zika virus introduction and transmission in resource-limited countries in Africa and the Asia-Pacific region: a modelling study. Lancet Infect Dis 16: 1237-1245. 